\title{
NOVAS DIRETRIZES EDUCACIONAIS E NOVOS PROJETOS PEDAGÓGICOS - (ETFRN E CEFET-RN): ENTRE O PENSAR E O FAZER
}

\author{
U. Á. PEREIRA ${ }^{1 *}$ e M. FRANÇA ${ }^{2}$ \\ 'Instituto Federal de Educação, Ciência e Tecnologia do Rio Grande do Norte \\ ${ }^{2}$ Universidade Federal do Rio Grande do Norte \\ ulisseia.avila@ifrn.edu.br
}

Artigo submetido em agosto/2015 e aceito em outubro/2015

DOI: 10.15628/holos.2015.3351

\section{RESUMO}

Este artigo trata da implementação da Proposta Curricular da Escola Técnica Federal do Rio Grande do Norte no ano de 1995 e do Projeto Político-Pedagógico do Centro Federal de Educação Tecnológica do Rio Grande do Norte em 2005. Analisamos os documentos específicos e a legislação que nortearam as diretrizes à implementação da Proposta. Os resultados apontam que a compreensão dos princípios norteadores desses documentos por parte da maioria dos professores contribuiu para alguns avanços nas atividades de ensino e na redefinição do trabalho da equipe pedagógica, bem como ao desenvolvimento de ações mais direcionadas à integração entre ensino, pesquisa e extensão.

PALAVRAS-CHAVE: Proposta curricular. Projeto Político-Pedagógico. ETFRN. CEFET-RN.

\section{NEW EDUCATIONAL GUIDELINES AND NEW PEDAGOGICAL PROJECTS - (ETFRN AND CEFET-RN): BETWEEN THINKING AND DOING}

\section{ABSTRACT}

This article deals with the implementation of the Curriculum Proposal of the Federal Technical School of Rio Grande do Norte, in 1995 and the PoliticalPedagogical Project of the Federal Center of Technological Education of Rio Grande do Norte, in 2005. It was analyzed the specific documents and legislation that guided the guidelines for the implementation of the Proposal. The results show that the understanding of the guiding principles of these documents by the majority of teachers contributed to some advances in teaching and in the redefinition of the pedagogical team work as well as the development of more targeted actions for the integration of teaching, research and extension.

KEYWORDS: Curriculum Proposal. Political-Educational Project. ETFRN. CEFET-RN. 


\section{INTRODUÇÃO}

No presente artigo, apresentamos os resultados relativos à implementação da Proposta Curricular da Escola Técnica Federal do Rio Grande do Norte (ETFRN) elaborada no período 19931994 e do Projeto Político-Pedagógico do Cefet-RN, construído no ano de 2004, cujas ações ocorreram de forma participativa.

Para levar a efeito o estudo, é pertinente fazermos referência a vários documentos, dentre eles: Lei n. 5.691/71 que fixou as Diretrizes e Bases para o ensino de $1^{\circ}$ e $2 \stackrel{\circ}{\circ}$ graus, LDB n. 9.394/96 que estabelece as diretrizes e bases da educação nacional; Decreto n. 2.208/97 que regulamentou o § 2 o do art. 36 e os arts. 39 a 42 da Lei n. 9.394, de 20 de dezembro de 1996, que estabelece as diretrizes e bases da educação nacional; Decreto n. 5.154/2004 que regulamenta o § 20 do art. 36 e os arts. 39 a 41 da Lei n. 9.394, de 20 de dezembro de 1996, que estabelece as diretrizes e bases da educação nacional; Parecer CNE/CEB n. 39/2004 que trata da aplicação do Decreto $n$. 5.154/2004 na Educação Profissional Técnica de nível médio e no Ensino Médio; e Resolução n. 1/2005 que atualiza as Diretrizes Curriculares Nacionais definidas pelo Conselho Nacional de Educação para o Ensino Médio e para a Educação Profissional Técnica de nível médio às disposições do Decreto n. 5.154/2004. Ademais, recorremos a autores como Ciavatta (2005), Frigotto (2005) e Ramos (2002) que discutem as políticas de ensino médio e de educação profissional. Portanto, os resultados sinalizam a compreensão da mencionada Proposta Curricular e referido Projeto, nas suas especificidades.

A Proposta Curricular da ETFRN rompeu com a rigidez da estrutura dos cursos técnicos em nível médio organizados em regime seriado semestral, voltados estritamente para a ocupação de postos específicos no mercado de trabalho, tendo como princípios norteadores do currículo: a concepção de educação como instrumento básico de conhecimento; a concepção de universalidade de ciência; a superação da dicotomia teoria/prática; a formação de atitudes e conviç̧ões; a percepção das relações entre sociedade, trabalho e escola; a definição de um projeto pedagógico coletivo e de um plano de valorização e capacitação dos educadores dessa Instituição.

Por outro lado, o Cefet-RN, denominado desde 2008 de Instituto Federal de Educação, Ciência e Tecnologia do Rio Grande do Norte (IFRN) e recebendo, ao longo dos anos, diferentes denominações, em função de novas diretrizes implementadas pelo governo federal, assumiu, em seu Projeto Político-Pedagógico implementado em 2005 uma visão de homem como um ser histórico-social; o trabalho como princípio educativo, implicando uma formação baseada no processo histórico e ontológico de produção da existência humana; a pesquisa como princípio educativo, possibilitando a construção de autonomia intelectual; a compreensão de que a realidade concreta é uma totalidade interdisciplinar.

\section{REFORMULAÇÃO E IMPLEMENTAÇÃO DE PROPOSTA CURRICULAR DA ESCOLA TÉCNICA FEDERAL DO RIO GRANDE DO NORTE (ANOS 1980-1990).}

A partir dos anos 1980 - década emblemática quanto ao aprofundamento da crise do capital e das transformações no mundo do trabalho - a reestruturação do processo produtivo adquiriu novo impulso com a inclusão das novas tecnologias no processo de trabalho levando a uma superação gradativa do modelo Taylorista/Fordista como fator de regulação da produção. 
Esse modelo, não respondendo às novas demandas do processo de trabalho, concorreu para o surgimento de novos modos de regulação, fundamentados nos sistemas flexíveis de organização do trabalho.

Assim, paralelo à produção, desenvolveu-se um modelo de organização da produção denominado por Harvey (1993, p. 140) de acumulação flexível que segundo ele,

se apoia na flexibilidade dos processos de trabalho, dos mercados de trabalho, dos produtos e padrões de consumo. Caracteriza-se pelo surgimento de setores de produção inteiramente novos, novas maneiras de fornecimento de serviços financeiros, novos mercados e, sobretudo, taxas altamente intensificadas de inovação comercial, tecnológica e organizacional. A acumulação flexível envolve rápidas mudanças dos padrões do desenvolvimento desigual, tanto em setores como entre regiões geográficas [...].

Em face desse contexto, no ano de 1988, iniciou-se o projeto de reformulação curricular da ETFRN, quando o Ministério da Educação, por meio da Secretaria Nacional de Educação Média e Tecnológica (Semtec), decidiu revisar a parte de formação especial, abrangendo inclusive as grades curriculares, conteúdos programáticos, perfis profissionais, metodologia, avaliação do processo ensino-aprendizagem sob a coordenação do Centro Federal de Educação Tecnológica de Minas Gerais. Tendo em vista a morosidade desse projeto do Cefet/MG, a Direção da ETFRN, em 1993, com a aprovação e o apoio da Semtec/MEC, resolveu retomar o processo de reformulação curricular contando com a participação maciça de todos os segmentos da Escola.

Nesse sentido, a Instituição organizou um "grupo de sistematização, para analisar todas as informações, textos e sugestões provenientes dos demais grupos, tomando por referência alguns princípios do planejamento participativo" (ESCOLA TÉCNICA FEDERAL DO RIO GRANDE DO NORTE, 1997, p. 12). Ocorreram várias discussões sobre as concepções de homem, sociedade, educação, escola, currículo, ensino, trabalho e interdisciplinaridade junto a professores e profissionais que mantinham contato direto com os estudantes, além dos representantes de turma, dos centros de atividades, do grêmio e discentes.

A Instituição tomando por base uma concepção histórico-crítica do processo social, segundo a qual os fatos sociais mantêm entre si uma conexão recíproca, são determinados e determinantes da sociedade, enquanto totalidade, definiu os princípios norteadores do currículo apresentando as seguintes características: a) concepção de educação como instrumento básico de conhecimento; b) concepção de universalidade de ciência; c) superação da dicotomia teoria/prática; d) formação de atitudes e convicções; e) percepção das relações entre sociedadetrabalho-escola; f) definição de um projeto pedagógico coletivo; g) definição de um plano de valorização e capacitação dos educadores da ETFRN (ESCOLA TÉCNICA FEDERAL DO RIO GRANDE DO NORTE, 1997).

Essa Proposta Curricular compreende, também, indicações teórico-práticas, oriundas dos professores da ETFRN e apresenta uma visão dos resultados a curto, médio e longo prazos: a) uma mudança de postura teórico-prática dos segmentos envolvidos com a formação técnico-profissional, no sentido de superar a dicotomia formação do homem cidadão/formação do técnico-profissional; b) uma formação técnico-profissional que considere a perspectiva de vinculação entre cidadania e tecnologia; c) um conjunto de estratégias que possibilitem a 
materialização de padrões de qualidade da gestão educacional e da ação pedagógica, bem como o aprimoramento dos recursos humanos, a partir da implementação da nova proposta curricular (ESCOLA TÉCNICA FEDERAL DO RIO GRANDE DO NORTE, 1995, p.24).

Os cursos técnicos de Edificações, Eletrotécnica, Estradas, Geologia, Mecânica, Mineração e Saneamento - antes fragmentados e que, segundo os docentes da ETFRN vinham entravando a inserção dos estudantes no mercado de trabalho, foram extintos e transformados nas seguintes áreas de conhecimento: Construção Civil, Eletromecânica, Informática, Serviços e Tecnologia Ambiental, com suas respectivas habilitações.

Essas áreas eram entendidas como um conjunto de matérias afins, organizadas de modo a "assegurar um saber sistematizado e uma base tecnológica comum, capaz de possibilitar maior diversidade de habilitações profissionais que permitam ao aluno a escolha de uma ocupação técnica adequada aos seus reais interesses e às exigências do mundo produtivo" (ESCOLA TÉCNICA FEDERAL DO RIO GRANDE DO NORTE, 1995, p. 80).

Desse modo, as citadas áreas tinham como objetivos transmitir e gerar conhecimentos científicos que fundamentassem o processo produtivo; desenvolver habilidades instrumentais básicas das formas diferenciadas de linguagem próprias das diferentes atividades sociais e produtivas.

Ademais, desenvolveram categorias de análise que propiciaram a compreensão do processo histórico-crítico da sociedade e das formas de atuação do homem, enquanto cidadão e trabalhador, sujeito e objeto da história.

Após vários estudos e discussões, teve início a construção da grade curricular, estruturada em base científica e tecnológica: conhecimentos científicos e tecnológicos comuns; conhecimentos científicos tecnológicos específicos, tendo, como princípio básico do novo currículo, a formação omnilateral do técnico-cidadão para o domínio dos recursos científicos e tecnológicos. Esses recursos possibilitariam aos estudantes a atuação no sistema produtivo e a participação crítica no processo de transformação social, em função dos interesses coletivos.

Para Manacorda (2007. p. 89), “a omnilateralidade é, portanto, a chegada histórica do homem a uma totalidade de capacidades de consumo e prazeres, em que se deve considerar, sobretudo, o gozo daqueles bens espirituais, além dos materiais, e dos quais o trabalhador tem estado excluído em conseqüência da divisão do trabalho".

Nesse contexto, o estágio supervisionado, totalizando uma carga horária de trezentas e sessenta horas, era contemplado na grade curricular de cada área de conhecimento.

Dessa forma, o estudante cursava a área de conhecimento em três anos, e, ao final, optava por uma habilitação profissional correspondente à área que cursava no quarto ano. O primeiro semestre letivo desse último ano destinava-se às disciplinas relativas aos conhecimentos científicos e tecnológicos comuns e específicos; o segundo, ao estágio supervisionado.

Diante disso, a avaliação assumia as funções de diagnóstico, formativa e somativa, incluindo a recuperação paralela entendida como "estratégia para reorientar o estudante no processo de construção do conhecimento, especificamente, quanto ao domínio dos conteúdos não assimilados, respeitando as diferenças socioculturais e o seu ritmo de aprendizagem" (ESCOLA TÉCNICA FEDERAL DO RIO GRANDE DO NORTE, 1997, p.103). 
Assim, em 1995, essa Proposta foi implementada sob a égide da Lei de Ensino n. 5.692/71, assim como do Parecer do CNE n. 45/72, que fixava os mínimos das habilitações profissionais.

Nesse ano, foram elaborados os indicadores de avaliação para todos os segmentos da Escola e redigidos os relatórios referentes ao primeiro e segundo anos da implementação da Proposta Curricular.

No ano de 1996, ocorreu a descontinuidade dessa Proposta Curricular, em decorrência da promulgação da Lei de Diretrizes de Bases da Educação Nacional, Lei n. 9.394/96 e promulgação do Decreto n. 2.208/97 que se tornou um dos instrumentos legais de consolidação da reforma da educação profissional, ao assumir propostas pedagógicas de cunho neoliberal, culminando, assim, com a separação do ensino médio de caráter propedêutico da educação profissional.

Mediante esse processo, houve a necessidade premente de a ETFRN de proceder a uma mudança curricular, em decorrência das interferências das políticas educacionais, à época, que determinavam ou re-orientavam a prática escolar, em função dos interesses do setor produtivo.

Assim sendo, a citada LDB veio proporcionar nova reforma, priorizando a formação dos indivíduos e, consequentemente, adaptando-os às necessidades requeridas pelo mundo contemporâneo.

Essa LDB permitiu que o Decreto n. 2.208/97 estabelecesse as bases da reforma da educação profissional determinando uma organização curricular independente do ensino médio, impedindo, portanto, a busca por uma concepção unitária que inclusive integraria a formação profissional ao ensino médio.

\section{O PROCESSO DE CONSTRUÇÃO E IMPLEMENTAÇÃO DO PROJETO POLÍTICO- PEDAGÓGICO DO CEFET-RN (2004)}

Em 2003, o Cefet-RN adotou alguns procedimentos como, por exemplo, a avaliação das suas diversas ofertas de ensino; essa decisão foi tomada após reflexões feitas por seus diversos segmentos a respeito dos currículos vigentes. Nesse sentido, foi realizada uma autoavaliação no âmbito dos seus diversos grupos que evidenciou as implicações da Reforma da Educação Profissional e do Programa de Expansão da Educação Profissional (Proep) na Instituição.

Assim, o Cefet-RN constatou, também, que não havia um projeto integrador entre as licenciaturas de Física e de Geografia. As áreas de pesquisa, extensão e ensino apresentavam problemas de articulação, ocorrendo entraves quanto à operacionalização desses currículos, em termos pedagógicos e administrativos. Não existia um projeto que contemplasse o nível tecnológico da educação profissional, tampouco diretrizes institucionais para os cursos em nível básico da educação profissional, destinados à qualificação e à reprofissionalização de trabalhadores, independente de escolaridade prévia.

Anterior à promulgação do Decreto n. 5.154/2004 que permite a oferta da educação profissional integrada ao ensino médio, possibilitando uma base sólida de conhecimentos científicos e tecnológicos integrados, o Cefet-RN iniciou o processo de construção do seu Projeto Político-Pedagógico, no ano de 2004, visando integralizar todas as suas ofertas formativas voltadas para o ensino, pesquisa e relações comunitárias e empresariais, possibilitando, assim, maior 
contextualização e significação às atividades acadêmicas, tendo como referência a sua função social.

Contando com a participação de pedagogas, professores e demais profissionais desenvolvem atividades junto aos estudantes e representantes discentes - foram realizadas pesquisas voltadas para a análise do funcionamento da Instituição, nos seus aspectos pedagógicos e administrativos, visando detectar as lacunas existentes entre: teoria e prática, sujeito e objeto, conhecimento e realidade.

Com base nesse diagnóstico, os vários segmentos da Instituição procederam a um estudo sobre as concepções de sociedade, ser humano, trabalho, cultura, educação e tecnologia que norteariam as decisões a serem trabalhadas no novo Projeto Político- Pedagógico, o qual deveria estar articulado aos objetivos e prioridades estabelecidas pela coletividade escolar.

A Instituição retomou a estruturação dos cursos em quatro anos, organizados sob uma base de conhecimentos científicos e tecnológicos, visando possibilitar ao educando uma habilitação profissional técnica de nível médio que também lhe daria direito à continuidade de estudos na educação superior.

Esse Projeto orientado para a formação integral, segundo Ciavatta (2005, p. 85), indica superar "a redução da preparação para o trabalho ao seu aspecto operacional, simplificado, escoimado dos conhecimentos que estão na sua gênese científico-tecnológica e na sua apropriação histórico-social". Está fundamentado em princípios que priorizam a inter-relação entre ciência, trabalho, educação, cultura e tecnologia. Ademais, contempla diretrizes coerentes com esses princípios, com fulcro na realidade da Instituição, considerando a sua função social, fundamentada em elementos básicos, contidos na legislação educacional, na sua própria realidade e na realidade social, econômica, política e do mundo do trabalho.

Nesse contexto, o Projeto está voltado para a compreensão do homem como um sujeito político, um cidadão que busca a autonomia, a autorrealização e a emancipação por meio de sua participação responsável e crítica nas esferas socioeconômicas e políticas.

Compreendemos que essa concepção sinaliza a necessidade de articulação entre formação geral e específica, teoria e prática, possibilitando aos sujeitos a produção de conhecimentos decorrentes de sua ação sobre a natureza.

Tal documento enfatiza, pois, a educação como um processo formativo do educando, nos campos: biológico, psicológico, político, cultural, econômico e social, considerando a aquisição, a construção e a reconstrução dos conhecimentos, de valores e de princípios éticos, essenciais ao indivíduo no convívio social e para ele, num determinado contexto espacial e temporal, bem como para que possa intervir na sociedade, em função de sua transformação.

Ressalvamos que, nesse contexto, a Instituição busca romper com a visão de educação reduzida a uma condição mercantil, ao propor uma educação plena para a vida, em contraposição ao discurso da pedagogia das competências que tem, dentre os seus fundamentos, o individualismo e a competição e que, no entender de Kuenzer (2000, p. 21),

dissolve a dialética entre educação e ensino, ao pretender reduzir, na prática, o geral ao específico, o histórico ao lógico, o pensamento à ação, o sujeito ao objeto (em particular na informática), o tempo de vida ao tempo escolar, a riqueza dos processos educativos sociais e produtivos ao espaço escolar; no discurso, o 
movimento é inverso, de negação da redução, ampliando as funções da escola e Ihe atribuindo um novo messianismo, na medida em que the confere finalidades que, de longe, ultrapassam as suas possibilidades.

Nessa perspectiva, a pedagogia das competências deve ser superada, uma vez que segundo Frigotto (2004), reduz a atividade criativa e criadora do trabalho a um conjunto de tarefas.

Em contraposição a essa pedagogia, o Projeto Político-Pedagógico do Cefet-RN traz uma concepção de currículo, entendido como um conjunto integrado e articulado de atividades, pedagogicamente concebidas, a partir de uma determinada visão de homem, de mundo, de sociedade, de trabalho, de cultura, de educação, de ciência e tecnologia organizadas. A compreensão do currículo

se constitui um instrumento de mediação para o domínio do conhecimento científico: para o desenvolvimento do pensamento lógico, construtivo e criativo: para a formação de atitudes e conviç̧̃̃es, e, conseqüentemente, para a efetiva participação social, política, cultural e no mundo do trabalho" (CENTRO FEDERAL DE EDUCAÇÃO TECNOLÓGICA DO RIO GRANDE DO NORTE, 2003, p. 101).

Para Ramos (2004), o objetivo de um currículo integrado "não é a formação de técnicos, mas a formação de pessoas que compreendam a realidade e que possam atuar como profissionais".

Inferimos que esse currículo poderá favorecer a Instituição a definir ações educativas, no sentido da integração teoria-prática, entre o saber e o saber fazer, ou seja, a inserção dos estudantes como sujeitos históricos, construtores do próprio processo de aprendizagem.

A esse propósito, Machado (2010, p. 82) argumenta que:

Na perspectiva de um currículo integrado [...] um bom ponto de partida se refere à integração entre as finalidades e os objetivos da escola à prática pedagógica, tornando-os efetivamente concretos. É importante também lembrar da dimensão integral da vida do educando; entendê-lo como alguém que, além de estudante, tem outros papéis no sistema de relações sociais.

Em face da compreensão de currículo e, conforme a citação acima, há similaridade com o enfoque atribuído pelo Cefet-RN:
a) homens e mulheres, capazes de transformar a realidade; b) o trabalho como princípio educativo, permitindo uma compreensão do significado econômico, social, histórico, político e cultural das ciências e das artes; c) a pesquisa como princípio educativo por possibilitar a construção de autonomia intelectual do educando, devendo estar orientada ao estudo e à busca de soluções para as questões práticas do cotidiano do estudante; d) a realidade concreta como síntese das múltiplas relações; e) a interdisciplinaridade; f) a contextualização; g) a flexibilidade entendida pela Instituição como uma das bases epistemológicas relevantes do currículo (CENTRO FEDERAL DE EDUCAÇÃO TECNOLÓGICA DO RIO GRANDE DO NORTE, 2004, p. 98).

Para a operacionalização do currículo, segundo os princípios explicitados, encontram-se definidos, também no Projeto: a) o papel do professor entendido como mediador da aprendizagem 
do processo ensino-aprendizagem; b) a avaliação de forma contínua e sistemática, considerada em suas múltiplas dimensões; c) a relação professor-aluno, enquanto ação transformadora e de promoção social; d) a inclusão de pessoas com necessidades educativas especiais; e) a unidade ensino/pesquisa; f) a organização dos conteúdos de ensino; g) a unidade ensino/pesquisa; h) a política da educação a distância em que a Instituição se propõe a incluir essa educação em suas ofertas educacionais; isso implica, também, a necessidade de avaliações sistemáticas anuais dos seus projetos; i) a avaliação do projeto político-pedagógico.

Observamos que a Instituição expressa o seu entendimento de trabalho como fonte de produção e de saberes, essenciais à existência humana, no sentido de formar indivíduos capazes de atuar como dirigentes e cidadãos, conforme expressa, também, Gramsci (2006). Diante disso, identifica-se a busca pela integração entre homo faber e homo sapiens, ao conceber a relação trabalho e educação como indissociável.

O sentido de flexibilidade assumido pelo Projeto Político-Pedagógico não se confunde com o aligeiramento e a precarização da formação humana, pois, como enfatizam Baracho, Silva, Moura e Pereira (2005, p. 32), "ao contrário devemos assumir a responsabilidade com a formação de cidadãos críticos, reflexivos, éticos e comprometidos com as transformações sociais e coletivas voltadas para a construção de uma sociedade justa e igualitária".

Para a operacionalização do currículo e coerentes com os princípios explicitados, encontram-se definidas diretrizes, tais como: o professor entendido como mediador da aprendizagem; a avaliação contínua e sistemática, imprimindo significado ao trabalho escolar e docente.

Pelo exposto, compreendemos que há necessidade de que sejam asseguradas as condições administrativas e pedagógicas à operacionalização do currículo integrado.

\section{A TíTULO DE CONCLUSÃO}

Com este estudo, chegamos à conclusão de que a Proposta Curricular da ETFRN não foi elaborada meramente para atender ao perfil do "novo" trabalhador fundamental à lógica do capital, uma vez que considerava os princípios científicos tão relevantes quanto os princípios tecnológicos, como também a formação omnilateral que contraria a lógica maior do sistema capitalista.

Ressaltamos a atitude relevante de profissionais dessa Instituição em aproveitar as lacunas existentes na legislação vigente, para elaborar um currículo que buscou romper com o caráter tecnicista do ensino, tão presente, por exemplo, em escolas técnicas. Acreditamos que a educação deve considerar o homem em suas dimensões e não como mercadoria, valor de mercado ou meramente para a formação profissional.

Em relação ao Projeto Político-Pedagógico do Cefet-RN, este pressupõe uma ação intencionada com um sentido definido: a operacionalização do currículo integrado, exigindo transformação dos processos desenvolvidos no âmbito da Instituição, quer de caráter pedagógico, quer administrativo. Esse processo requer dinamismo, flexibilidade, autocrítica e gestão democrática, como caminhos a serem trilhados, a fim de reconhecer limites e superações, em face da objetividade em seu fazer. 
Consideramos que a Instituição, nesse Projeto, demonstrou alguns avanços, em termos conceituais no plano teórico, indicando caminhos cujo ponto de partida é o rompimento de uma relação educativa que separa o pensar do fazer, haja vista que o sujeito não deve ser o fetiche do mercado de trabalho do capital.

Nessa perspectiva, o Projeto avança no sentido de considerar a realidade como processo em constante mudança, não limitada ao domínio específico do mercado de trabalho, em que as suas demandas expressam contradições e conflitos do sistema econômico e político.

Visualizamos, também, que os princípios norteadores do Projeto, enquanto instrumentos democráticos, poderiam favorecer aos docentes a sistematização e o desenvolvimento de práticas interdisciplinares, a utilização de metodologias dinâmicas, promovendo, também, a valorização dos saberes adquiridos em espaços de educação não formal e a tomada de decisões participativas, além de ações voltadas à diversidade.

Isso se constitui em um desafio à Instituição na medida em que busca a formação sólida de conhecimentos científicos, humanísticos e tecnológicos, tendo como articuladores da organização curricular a ciência, o trabalho e a cultura. Articula, pois, parte e totalidade, visando superar a visão utilitarista do ensino em prol da formação integral.

É imperativo o acompanhamento e a avaliação do Projeto, por favorecer o confronto entre o que foi concebido e o que foi executado, sendo, pois, primordial o movimento dinâmico entre ação-reflexão-ação.

Compreendemos, ainda, que esses princípios e diretrizes materializados em práticas pedagógicas possibilitam a integração curricular, ultrapassando as fronteiras tradicionais entre a chamada formação científica e tecnológica, haja vista a formação do indivíduo como ser histórico e social.

Em face ao exposto, observamos que a compreensão dos princípios norteadores dos documentos articuladores da prática pedagógica contribuiu para que a maioria dos professores obtivesse alguns avanços no que diz respeito à sistematização de atividades de ensino que buscam a articulação e a inter-relação da teoria à prática.

Esses princípios caracterizaram instrumentos essenciais com vistas à reestruturação da sistemática do trabalho da equipe pedagógica cuja atuação junto aos estudantes favoreceu a melhoria do processo ensino-aprendizagem, haja vista a utilização de estratégias como: reuniões pedagógicas, de representantes de turmas e de conselhos de classe envolvendo professores, representantes dos discentes e pais, além de atividades realizadas semanalmente em sala de aula com os estudantes.

Portanto, a implementação da Proposta Curricular e, principalmente, do Projeto PolíticoPedagógico possibilitou à Instituição desenvolver ações mais voltadas para a integração ensino, pesquisa e extensão em um processo de interação com o mundo do trabalho e a sociedade em geral, possibilitando contextualização e significação às atividades acadêmicas.

\section{REFERÊNCIAS}

1. BARACHO, Maria das Graças; SILVA, Antonia Francimar da; MOURA, Dante Henrique; PEREIRA, Ulisséia Ávila. Algumas reflexões e proposições acerca do Ensino Médio Integrado à Educação 
Profissional Técnica de nível Médio. In: Ensino Médio Integrado à Educação Profissional: integrar para quê? Brasília: Ministério da Educação, Secretaria de Educação Básica, 2006.

2. ESCOLA TÉCNICA FEDERAL DO RIO GRANDE DO NORTE. Proposta Curricular. Revista da ETFRN, Natal, ano 11, n. 09, p. 25, janeiro, 1995.

3. eSCOLA TÉCNICA FEDERAL DO RIO GRANDE DO NORTE. Proposta Curricular: revisada e ampliada. Natal, 1997.

4. CENTRO FEDERAL DE EDUCAÇÃO TECNOLÓGICA DO RIO GRANDE DO NORTE. Projeto políticopedagógico: um documento em construção. Natal, 2003.

5. FRIGOTTO, Gaudêncio. A produtividade da escola improdutiva: um (re) exame das relações entre educação e estrutura econômico-social e capitalista. 6. ed. São Paulo: Cortez, 2001.

6. FRIGOTTO, Gaudêncio; CIAVATTA, Maria (Orgs.). Ensino médio: ciência, cultura e trabalho. Brasília: MEC, 2004.

7. FRIGOTTO, Gaudêncio: CIAVATTA, Maria; RAMOS, Marise (orgs.). Ensino médio integrado: concepção e contradições. São Paulo: Cortez, 2005.

8. GRAMSCl, Antonio. Cadernos do cárcere. Os intelectuais. O princípio educativo. O jornalismo. 4. ed. Rio de Janeiro: Civilização Brasileira, 2006.

9. HARVEY, David. A Condição Pós-moderna. São Paulo: Loyola, 1993.

10. KUENZER, Acácia Zeneida (Org.). Ensino Médio: construindo uma proposta para os que vivem do trabalho. São Paulo: Cortez, 2000.

11. MACHADO, Lucília. Ensino médio e técnico com currículos integrados: propostas de ação didática para uma relação não fantasiosa. In: MOLL, Jaqueline e colaboradores. Educação profissional e tecnológica no Brasil contemporâneo: desafios, tensões e possibilidades. Porto Alegre: Artmed, 2010.

12. MANACORDA, Mario Alighiero. Marx e a pedagogia Moderna. Campinas: Alínea, 2007. 